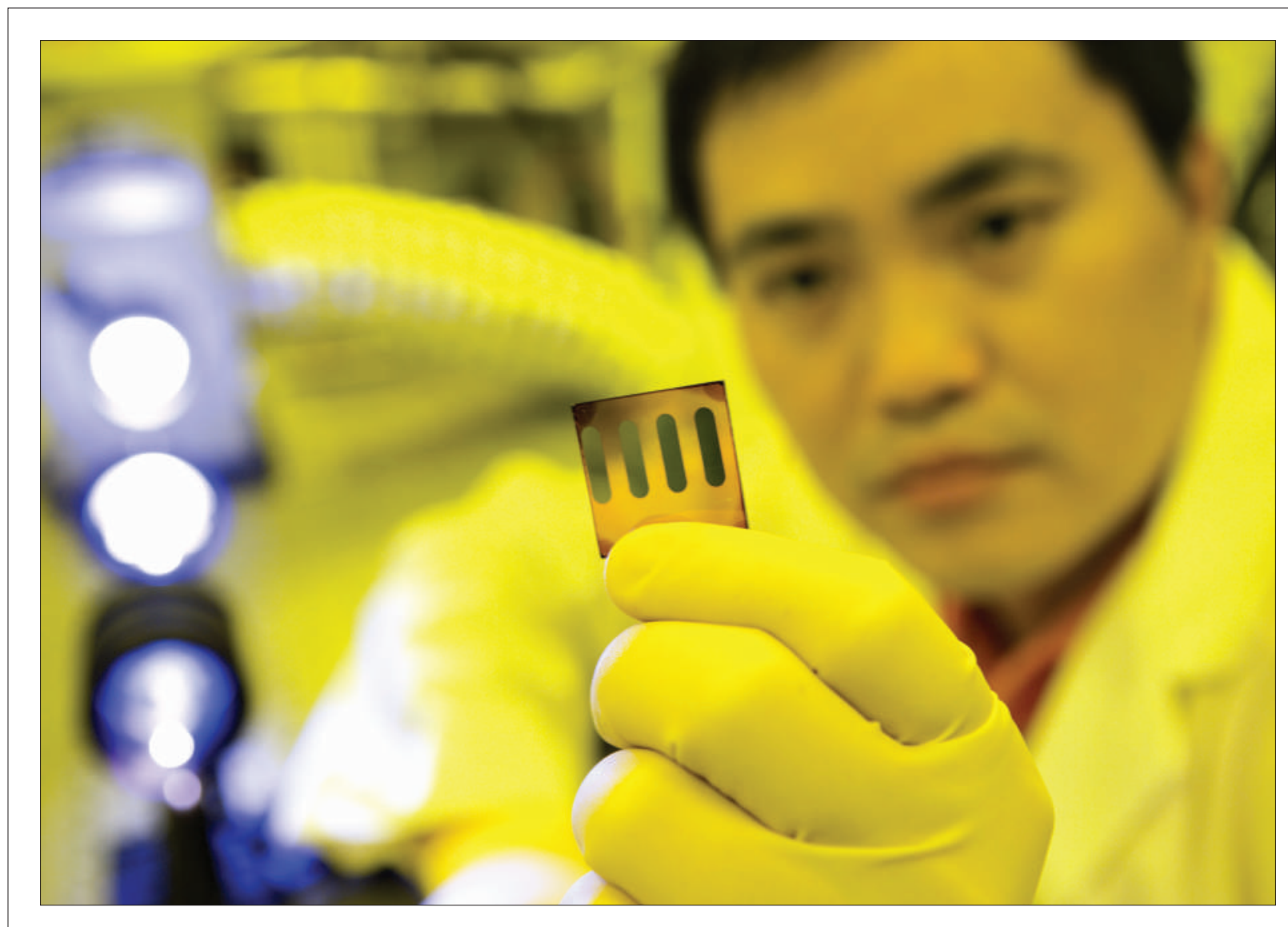

Singapore Journal of

Scientific Research

ISSN: 2010-006x 


\title{
Evaluation of Nutritional Composition of Papaya (Carica papaya L.) Genotypes using Genotype by Trait Biplot
}

\author{
${ }^{1}$ Timon Ogheneweware Emede, ${ }^{1}$ Babatope Samuel Ajayo and ${ }^{2}$ Collins Agho \\ ${ }^{1}$ Department of Crop Science, Faculty of Agriculture, University of Benin, P.M.B. 1154 Benin City, Edo State, Nigeria 300001, Nigeria \\ ${ }^{2}$ Plant Breeding Division, Nigerian Institute for Oil Palm Research (NIFOR), P.M.B. 1030, Benin City, Edo State, Nigeria 300001, Nigeria
}

\section{Abstract}

Background and Objective: The Genotype by Trait (GT) biplot can be used to compare cultivars based on multiple traits to identify parents to be used in plant breeding programs. The objective of this study was to evaluate the papaya lines based on GT biplot to examine its usefulness in visualizing the papaya trait relationship and its application in line comparison. Materials and Methods: The experiment was laid out as a randomized complete block design with three replications and 7 genotypes of papaya were studied. Data were collected on nutritional composition. Results: The two axes explained 81.3 and $65.6 \%$ of the total variation among the genotypes for proximate and mineral compositions respectively. There was a strong positive correlation between carbohydrate and dry matter content, ash, moisture and crude fiber content in the proximate compositions biplot, while the GT biplot for mineral contents indicated a strong positive correlation among the minerals, but they were negatively correlated with vitamin C. However, iron had a positive correlation with vitamin C. The study identified Cp002 and Cp007 as ideal genotypes based on the proximate composition, while for mineral composition it was Cp001. Conclusion: A hybrid between Cp002 or Cp007 and Cp001 would yield maximum value for the mineral and proximate contents in papaya.

Key words: Papaya, genotype-by-trait biplot, nutritional composition, correlation, ideal genotype

Citation: Emede, T.O., B.S. Ajayo and C. Agho, 2020. Evaluation of nutritional composition of papaya (Carica papayaL.) Genotypes using genotype by trait biplot. Singapore J. Sci. Res., 10: 458-465.

Corresponding Author: Department of Crop Science, Faculty of Agriculture, University of Benin, P.M.B. 1154 Benin City, Edo State, 300001 , Nigeria Tel: $+234(0) 8033803278$

Copyright: @ 2020 Timon Ogheneweware Emede et al. This is an open access article distributed under the terms of the creative commons attribution License, which permits unrestricted use, distribution and reproduction in any medium, provided the original author and source are credited.

Competing Interest: The authors have declared that no competing interest exists.

Data Availability: All relevant data are within the paper and its supporting information files. 


\section{INTRODUCTION}

The papaya (Carica papayaL.) belongs to the small family Caricaceae, which includes 35 species placed in six genera'. Among all species, 32 are dioecious, two trioecious and one monoecious ${ }^{2}$. The papaya is the only species of the genus Carica, also being the best known and most economically important within the family ${ }^{3}$, showing widespread cultivation in tropical and subtropical regions around the world. It is commonly known for its food and nutritional values throughout the world ${ }^{4}$. Papaya is a major fruit crop worldwide that is primarily consumed as fresh fruit. It is highly abundant and is commonly known as pawpaw in Nigeria. It is an invaluable plant that is prevalent throughout Tropical African and Nigeria is the fourth largest producer globally 5 . Practically, every part of papaya is of economic value and its use ranges from nutritional to medicinal. Papaya is a tropical fruit crop widely grown in Nigeria for food, ornamental and traditional health care purposes ${ }^{6}$. The fruit is an excellent source of essential nutrients such as iron, calcium, vitamins $A, B$, and $C^{7}$. Chewing the seeds of papaya helps to clear nasal congestion ${ }^{8}$ and is used in the treatment of intestinal worms ${ }^{9}$.

The ultimate goal of most breeders is to improve the productivity of crops as measured in terms of the yield performance or in value addition which includes nutritional quality. Plant breeding, in principle, involves the creation and exploitation of the genetic variation for different traits of economic importance ${ }^{10}$. Relationships among traits of economic importance impact the breeding strategies along with selection procedure. If all breeding objectives were positively correlated, selection would not be difficult than selecting for a single trait ${ }^{10}$. If all breeding objectives were either positively correlated or independently inherited, selection would not be too difficult either ${ }^{11}$, but breeding becomes challenging when there is a strong negative genetic correlation between traits which often exist ${ }^{12,13}$.

The genotype-by-trait (GT) biplot is a statistical tool for evaluating cultivars based on multiple traits and for identifying lines that are superior ${ }^{10}$. Entries identified for a particular trait or combination of several breeding traits could be candidates for use as parents in a breeding programme ${ }^{14}$. The GT biplot analysis allows visualization of genetic correlation among traits $^{15,16}$ and also helps in studying genotype by trait relationships. Yan and Rajcan ${ }^{14}$ reported that GT biplot can be used to compare genotypes based on multiple traits and identify genotypes that are particularly good in certain aspects and therefore candidates for parents in papaya breeding.
Analysis of papaya data with genotype and genotype by trait biplot that has a high advantage of showing the best performing genotype at the vertex of the polygon for a particular trait is rare. The objective of this research was to explain genotype evaluation on the basis of multiple traits using the GT biplot in order to reveal the interrelationship among papaya traits, to compare among different papaya genotypes on the basis of multiple traits and to recommend possible selection strategies for genetic improvement of papaya.

\section{MATERIALS AND METHODS}

Experimental site: The experiment was conducted at the Teaching and Research Farm of the Faculty of Agriculture, University of Benin, Benin City, Edo State, Nigeria (Latitude: $6^{\circ} 33 \mathrm{~N}$, Longitude: $5^{\circ} 37 \mathrm{E} ; 79$ masl). Field evaluation of the papaya genotypes was carried out from October 2014 - June 2015. The nutritional analysis was carried out in the Faculty of Agriculture Main Laboratory from January-June, 2015.

Materials and research tools: Seven pawpaw genotypes were used in this study viz: Cp001, Cp002, Cp005, Cp006, Cp007, $\mathrm{Cp008}$, and $\mathrm{Cp} 011$. They were obtained from the Uselu market and home gardens in Benin City metropolis. The collection was undertaken in October 2013. The seeds of each papaya accessions were sown in October 2013 in drill rows of $4 \mathrm{~m}$ by broadcasting and gradually thinned to three plants per row, spaced at $2 \times 2 \mathrm{~m}$. The experiment was laid out as a randomized complete block design with three replications.

Research procedure: At flowering, about 9 months after planting, NPK 15:15:15 was applied at the rate of $0.6 \mathrm{~kg} / \mathrm{plant}$. Each papaya stand received an additional $0.6 \mathrm{~kg}$ of NPK 15:15:15 at 18 months after planting. Weeds were controlled manually throughout the period of the study. The fruits were harvested at about one year after planting when the first fruit was matured and ripe for harvesting. The fruits used for nutritional analysis were cleansed and peeled. The seeds were removed and the flesh sliced into pieces and carefully wrapped in aluminum foil and oven-dried at $68^{\circ} \mathrm{C}$ to constant weight, milled and stored in clean plastic containers.

Data collection: Proximate analysis of moisture, crude protein, lipid, crude fiber, dry matter and ash was done as described by the standard method of $A O A C^{17}$. Crude protein $(N \times 6.25)$ was determined by the Kjeldahl method. Crude lipid was done by 
the Soxhlet extraction method ${ }^{17}$. The mineral analysis was determined by the dry ash extraction method as described by $\mathrm{AOAC}^{17}$. Vitamin $\mathrm{C}$ analysis was determined by titrimetric method $^{18}$. All the determinants were done in triplicates.

Experimental design: The laboratory analysis was carried out following the field plan of a randomized complete block design with three replications.

Parameters measured: Proximate analysis of Moisture Content (MC), Crude Protein (CP), Lipid Content (LP), Crude Fiber (CF), Dry Matter (DM), carbohydrate (CHO) and ash content (ASH) of the fruit pulp of papaya were determined on a dry weight basis and expressed in percentage. Vitamin $C$ (Vit C) and mineral composition of phosphorus (P), iron (Fe), calcium (Ca) and magnesium ( $\mathrm{Mg}$ ) were determined on a dry weight basis and expressed in grams.

Statistical analysis: The Genotype by Trait (GT) biplot approach ${ }^{14}$ was used to display the genotype by trait data in a biplot based on the formula reported by Neyhart et al. ${ }^{10}$. Because $n=2$ in a biplot, only (principal components 1 and 2 ) PC1 and PC2 were retained in the model and such a model tends to be best for extracting patterns and rejecting noise from the data. A Genotype by Trait (GT) biplot was constructed by plotting $\mathrm{PC} 1$ scores against $\mathrm{PC} 2$ scores for each genotype and each trait ${ }^{14}$. The biplot analysis was according to Model 2 (Transform $=0$ ) within-trait standard deviation standardized $($ Scale $=1)$, and trait-centred (Centering $=2$ ). The polygon views were based on genotype-focused Singular Value Partitioning (SVP $=2)$, while the vector views were based on the trait-focused singular value partitioning and were therefore appropriate for visualizing the relationships among traits and genotypes.

\section{RESULTS}

Total variation: The GT biplot for the papaya dataset, explained $81.3 \%$ of the total variation of the standardized data (Fig. 1). The first two principal components (PC 1 and PC 2) explained 55.4 and $25.9 \%$, respectively.

\section{Characters association and identification of winning genotypes: A strong positive association among $\mathrm{CHO}$ and $\mathrm{DM}$,} CF and MC, ASH and MC, ASH and LP, a moderate positive association between $\mathrm{DM}$ and $\mathrm{LP}$, between $\mathrm{CP}$ and $\mathrm{CHO}$, and CF with ASH were observed (Fig. 1). There was a negative correlation between $\mathrm{CP}$ with $\mathrm{LP}, \mathrm{CF}$ with $\mathrm{LP}, \mathrm{CF}$ and $\mathrm{CHO}, \mathrm{CF}$ and $\mathrm{DM}, \mathrm{MC}$ with $\mathrm{DM}, \mathrm{MC}$ with $\mathrm{CHO}$ as indicated by the near an angle of approximately 180 degrees $(r=\cos 180=-1)$. For mineral compositions, a strong positive correlations existed among the minerals but however, they were negatively

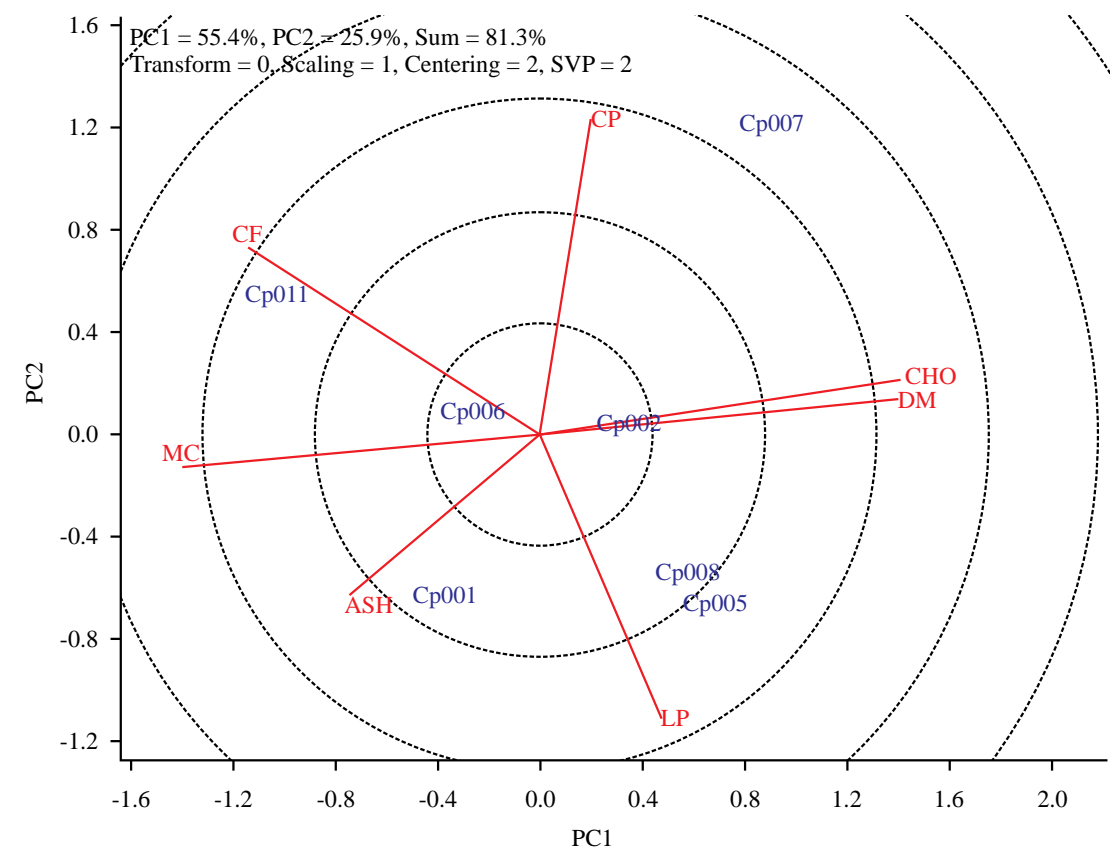

Fig. 1: Vector view of genotype by trait biplot, showing the interrelationship among all measured traits for the genotypes PC: Principal component, MC: Moisture content, ASH: Ash content, LP: Lipid content, DM: Dry matter, CHO: Carbohydrate, CP: Crude protein, CF: Crude fiber 


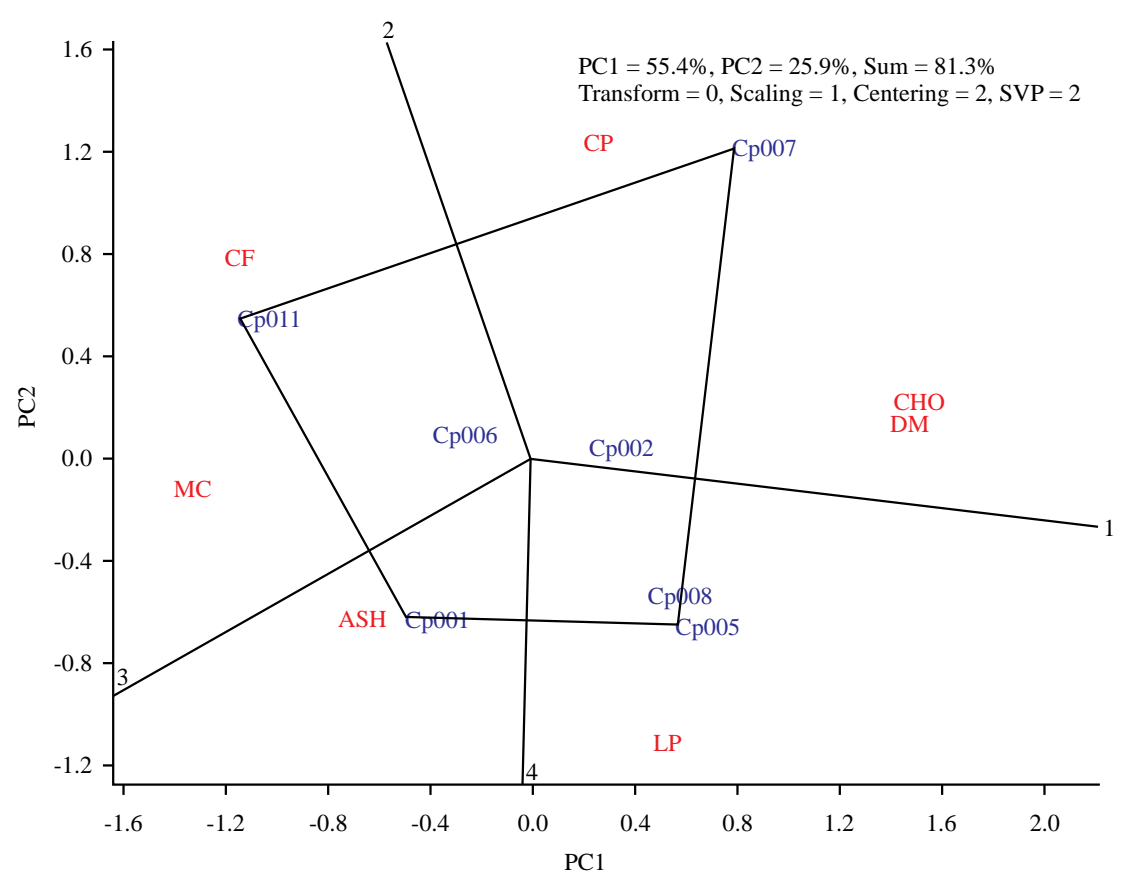

Fig. 2: Polygon view of genotype-by-trait biplot showing which genotype had the highest values for which traits

PC: Principal component, MC: Moisture content, ASH: Ash content, LP: Lipid content, DM: Dry matter, CHO: Carbohydrate, CP: Crude protein, CF: Crude fiber

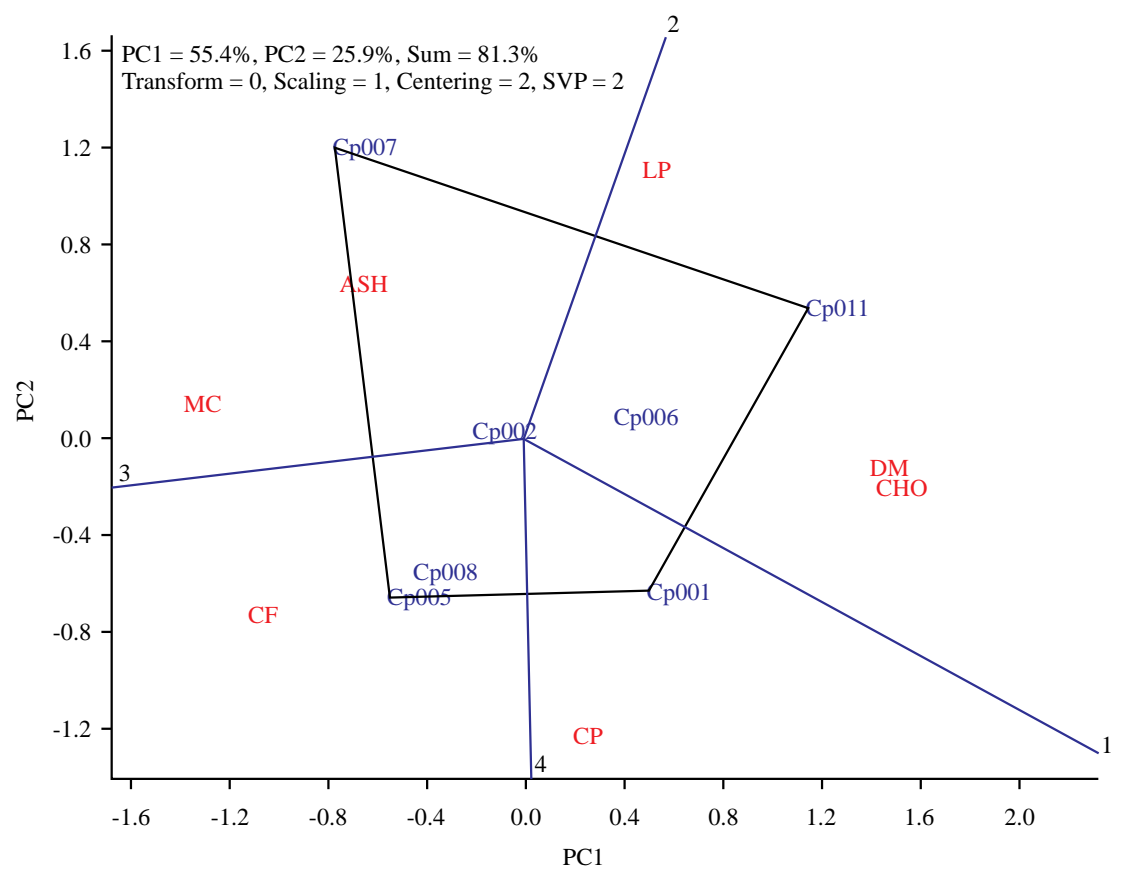

Fig. 3: "Which is worst for what " genotype x trait biplot of proximate composition of 7 papaya cultivars evaluated in Benin City, Nigeria. PC1 and PC2 explained $81.3 \%$ of the variation among cultivars

PC: Principal component, MC: Moisture content, ASH: Ash content, LP: Lipid content, DM: Dry matter, CHO: Carbohydrate, CP: Crude protein, CF: Crude fiber

correlated with Vit C content except iron that has positive correlation with Vit C. Figure 2 is biplots showing the polygon view of the genotype $x$ traits analysis on the nutritional composition based on principal component axes (PC1 and $P C 2)$. Figure 2 shows which cultivar(s) were best at what trait. The cultivar(s) at each vertex (vertex cultivar) of the polygon 


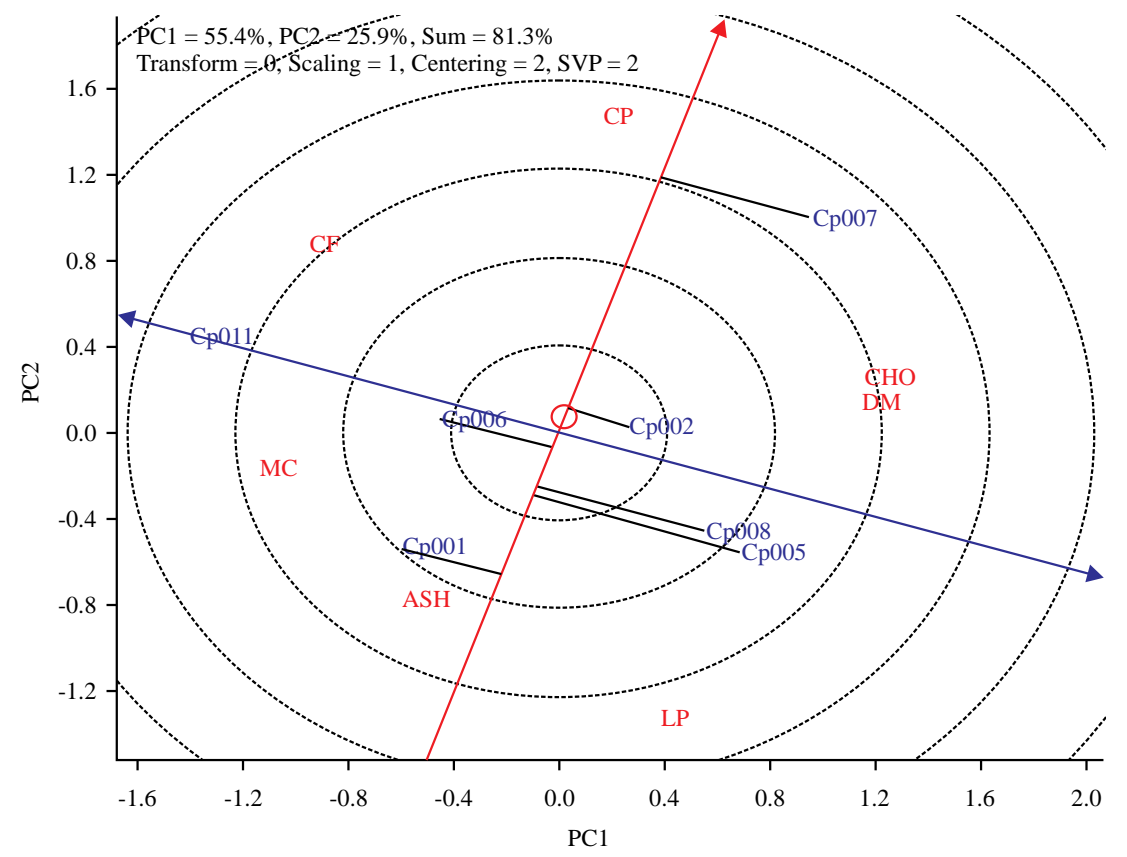

Fig. 4: An entry/tester genotypex trait biplot of proximate composition from 7 papaya genotypes evaluated at Benin City, Nigeria PC: Principal component, MC: Moisture content, ASH: Ash content, LP: Lipid content, DM: Dry matter, CHO: Carbohydrate, CP: Crude protein, CF: Crude fiber

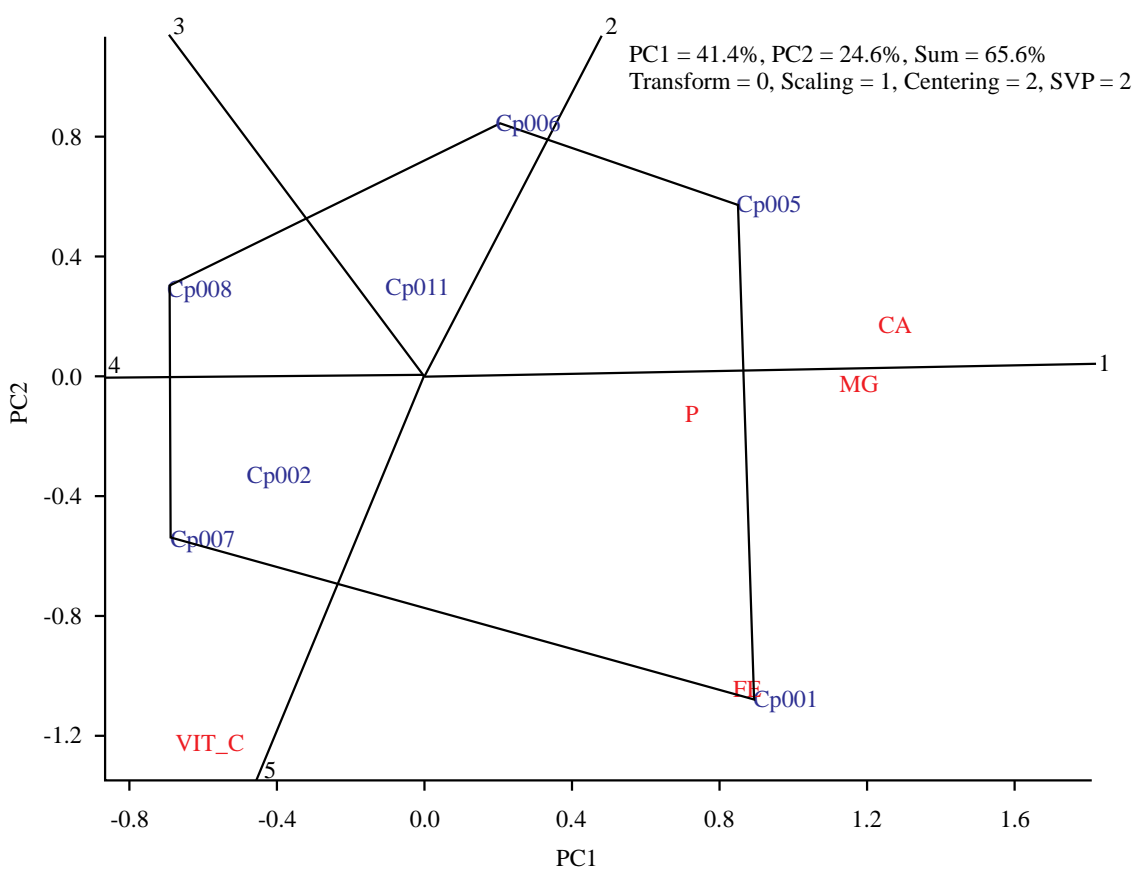

Fig. 5: Polygon view of genotype by trait biplot showing which genotype had the highest values for which traits . PC1 and PC 2 explained $65.6 \%$ of the variation among cultivars

PC: Principal component, CA: Calcium, FE: Iron, P: Phosphorus, MG: Magnesium

in the biplot were the best in terms of the trait(s) found within the sector demarcated by any two lines that meet at the origin of the polygon. From Fig. 2, Cp007 was the best in terms of
$\mathrm{CHO}, \mathrm{DM}$ and CP. The biplot in Fig. 3 was generated by choosing 'Reverse Sign of All Traits' function of the GGE (genotype main effect plus genotype-by-environment 


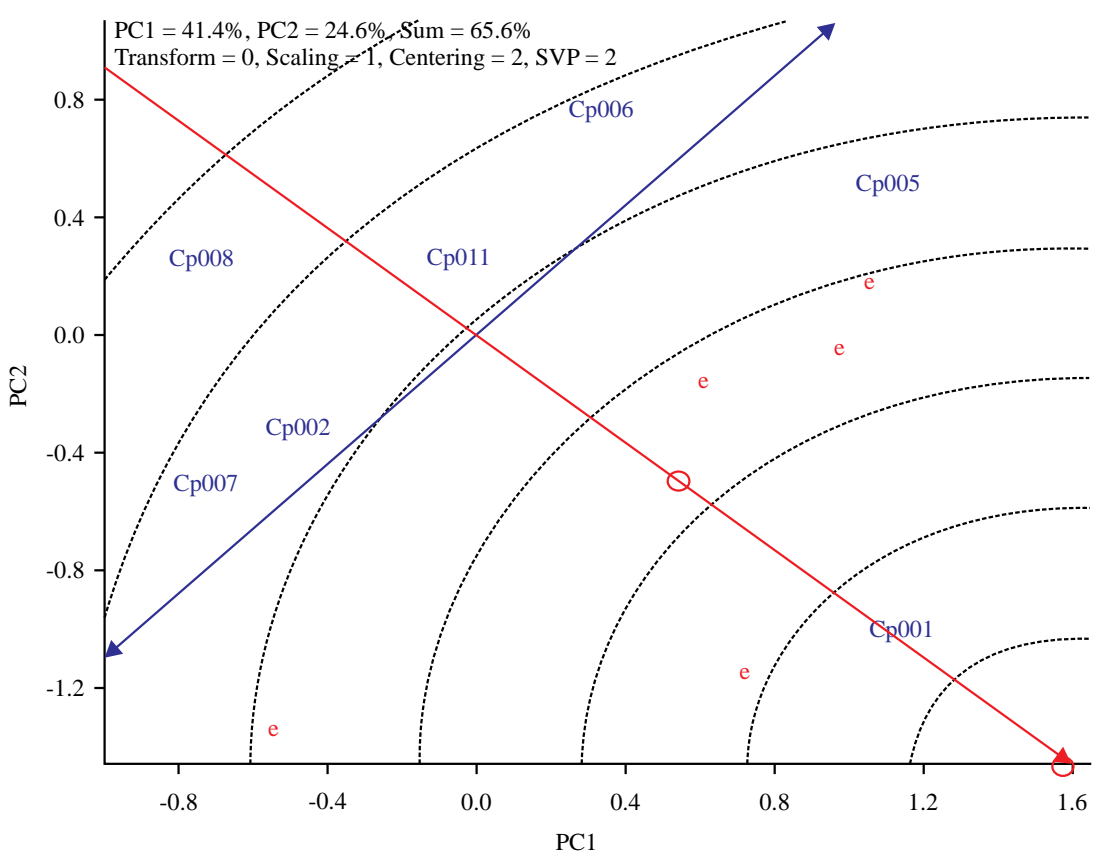

Fig. 6: An entry/tester genotype $x$ trait biplot of mineral composition from 7 papaya genotypes evaluated at Benin City, Nigeria. PC1 and PC 2 explained $65.6 \%$ of the variation among cultivars

PC: Principal component, e: Environment (Only one environment used)

interaction) biplot software to show the exact opposite of the biplot in Fig. 3. Cp001 was worst for LP, DM and CHO. Cp001 was worst for $\mathrm{CP}$, while $\mathrm{Cp} 005$ was worst for $\mathrm{CF}$. On the other hand, Cp007 was worst for ash and MC.

In the biplot displayed in Fig. 4, the single-arrow line that passes through the biplot origin is referred to as ATC (averagetester coordinate), and on this line is ranked the cultivars in terms of their nutritional performance. For mineral composition, Cp005, Cp001 and Cp007 were the winning genotypes and populations that are outstanding in these traits explained $65.6 \%$ of the total variation among the genotypes in the biplot (Fig. 5). Cp002 and Cp007 were closest to the position of an ideal cultivar based on the proximate compositions, while Cp001 was the ideal genotype for mineral compositions as shown in Fig. 6.

\section{DISCUSSION}

The relatively high percentage of variation observed reflects the complexity of the relationships among the measured traits of papaya. The two axes (PC1 and PC2) explained $81.3 \%$ of the total variation among the cultivars due to the nutritional traits measured. Cp007 was the best in terms of $\mathrm{CHO}, \mathrm{DM}$ and $\mathrm{CP}$, indicating that it could be used as parent in the development of varieties, hybrids and populations that are outstanding in these traits ${ }^{19}$. A strong positive association between $\mathrm{CHO}$ and $\mathrm{DM}$ and other traits suggested that the higher the $\mathrm{CHO}$, the higher the DM, although Oyeleke et a/.20 reported that low protein content in papaya samples studied could be as a result of increased sugar. The negative correlation between $\mathrm{CP}$ with $\mathrm{LP}$, indicated that an increasing $\mathrm{CP}$ causes LP to decrease. The GT biplot for the papaya dataset was based on Model 2 of Yan and Rajcan ${ }^{14}$ method. The traits were considered as the tester and the cultivars as entries ${ }^{21}$. Based on Otieno and Owuor ${ }^{22}$, Rubio et al. ${ }^{23}$ and Sabaghnia and Janmohammadi ${ }^{24}$, the basic structure among the traits should be captured by the biplots for better interpretations.

In the GT biplot, a vector is drawn from the biplot origin to each marker of the genotype to facilitate visualization of the relationships between and among the traits as well as genotypes. The polygon view of the GT biplot is useful for identification of genotypes with the highest values for one or more traits (which wins where or which is best for what genotypes). It normally involves connecting the genotypes with straight lines so that a polygon is formed with all other traits contained within the polygon. To find the relationship between two traits, the cosine of the angles between two traits is approximated with a negative value indicating a 
negative genotypic correlation and a positive value indicating a positive genotypic correlation, while a value of zero (angle $90^{\circ}$ ) shows independently inherited traits provided the biplot described a sufficient amount of the total variation which was $81.3 \%$ in this case. Badu-Apraku et a/.25,26 reported that the biplot generally accounted for small variation under stress environments, especially where the genotypes used were not specifically bred for tolerance to such stress. However, no studies have been carried out to specify when the proportion of variation explained by a biplot becomes too small to make a valid conclusion. However, it is generally assumed that any proportion below $40 \%$ is too small.

Cp011 was good for CF and MC. Cp001 was the best for ash content while $\mathrm{Cp} 005$ was the best for lipid content. Some cultivars did not win for any trait. However, Cp005, Cp001 and Cp007 were the winning genotypes, and it indicated that these genotypes could be used as parents in the development of hybrid. Some cultivars, though at the vertex did not win for any trait in their respective sector, an indication that they are not outstanding for any of the measured trait. Oladejo et al.27, working on cowpea cultivars also reported some cultivars with no trait in their respective sector. In the context of genotype-by- trait analysis, an ideal cultivar has been defined as the cultivar that combines several good traits in its genetic composition ${ }^{28}$. An ideal cultivar should possess the highest mean performance across traits (i.e., longest projection onto the average-tester coordinate or ATC abscissa and shortest entry-vector). Thus, it should be close to the ideal genotype represented by the innermost concentric circle with an arrow pointing to $\mathrm{it}^{29}$. Such ideal cultivar can, therefore, be used as a reference check in subsequent trials where the set of nutritional traits would be measured.

Oladejo et a/.27 reported that the double-arrow line, Average-Tester Coordinate (ATC) divides the ATC abscissa into two at the middle. The portion of the ATC towards the right displays the above average cultivars and towards the left shows those cultivars below average. Based on this biplot, the genotypes that performed above average were $\mathrm{Cp002}$ and Cp007, while the remaining cultivars performed below average in terms of nutritional composition. $\mathrm{Cp} 002$ and $\mathrm{Cp} 007$ were closest to the position of an ideal cultivar based on the proximate compositions, while $\mathrm{Cp} 001$ was the ideal genotype for mineral composition, because they combine several good traits in their genetic composition and desirable in terms of most of the traits and thus could serve as a good genetic raw material from which better cultivars, synthetic varieties and pure lines could be developed and a hybrid between $\mathrm{Cp002}$ or $\mathrm{Cp007}$ and $\mathrm{Cp} 001$ would yield maximum value for the mineral and proximate contents in papaya.
Thus, genotype-by-trait biplot is very useful in trait profile analysis and in identification of traits that are reliable for indirect selection of a target primary trait. However, the major limitation of this tool is lack of serious statistical tests for most of its graphical displays. However, its results have been found to be consistent with that of ANOVA, correlation, regression and multivariate statistical methods ${ }^{30,31}$. It is recommended that future research should combine the nutritional traits with yield in order to produce a genotype xyield $x$ trait (GYT) biplot. The GYT biplot can help the visual identification of the best genotype; it is better than the GT biplot method.

\section{CONCLUSION}

The genotype-by-trait (GT) biplot is a statistical tool for evaluating cultivars based on multiple traits and for identifying ideal genotypes. It allows visualization of genetic correlation among traits. The GT biplot has been used in this study to compare papaya genotypes on the basis of multiple traits and identify genotypes to be used as parents in papaya breeding program. Thus, the GT biplot is not only an excellent tool in genotype-by-trait data analysis, but is also useful in evaluating genotypex genetic marker data, multienvironment trial data and other two-way data.

\section{SIGNIFICANCE STATEMENT}

This study discovered that the genotype-by-trait (GT) analysis biplot is quite beneficial for plant breeders and agronomists to identify genotypes that are outstanding for certain traits, which could be used in crop improvement programme provided the biplot described a sufficient amount of the total variation. This study will help the researcher to uncover the critical areas of the full potential and weaknesses of this powerful tool that many researchers were not able to explore. However, the results of a GT biplot can be deficient if PC1 and PC2 account for only a small proportion of the total variation. Thus a new theory on GT biplot may be arrived at.

\section{REFERENCES}

1. Ramos, H.C.C., M.G. Pereira, L.S.A. Goncalves, A.P.C.G. Berilli, F.O. Pinto and E.H. Ribeiro, 2012. Multivariate analysis to determine the genetic distance among backcross papaya (Carica papaya) progenies. Genet. Mol. Res., 11: 1280-1295.

2. Ming, R., Q. Yu and P.H. Moore, 2007. Sex determination in papaya. Semin. Cell Dev. Biol., 18: 401-408. 
3. Droogenbroeck, V., P. Breyne, P. Goetghebeur, E. RomeijnPeeters, T. Kyndt and G. Gheysen, 2002. AFLP analysis of genetic relationships among papaya and its wild relatives (Caricaceae) from Ecuador. Theor. Applied Genet., 105: 289-297.

4. Krishna, K.L., M. Paridhavi and J.A. Patel, 2008. Review on nutritional, medicinal and pharmacological properties of Papaya (Carica papaya Linn.). Nat. Prod. Radiance, 7:364-373.

5. FAO, . FAO (Food and Agriculture Organization) of the United Nations statistics online website. 2002; 2004; 2007; 2008. http://faostat.fao.org.

6. Sofoware, A., 1997. Medicinal Plants used in Traditional Medicine in Africa. 1st Edn., John Wiley and Sons, New York, USA., pp: 128-129.

7. USDA, 2009. Agricultural research science. Agricultural research science. National nutrient data base for standard reference, release 22 , nutrient data laboratory home page: http://www.ars.usda.gov/ba/bhnrc/ndl.

8. Elizabeth, K., 1994. Immense Help from Nature Workshop. 1st Edn., Elikaf Health Services Ltd., Ikeja, Lagos, pp: 145.

9. Bouanga-Kalou, G., A. Kimbonguila, J.M. Nzikou, F.B. Ganongo-Po and F.E. Moutoula et al., 2011. Extraction and characteristics of oil seed from papaya (Carica papaya) in Congo Brazzaville. Asian J. Agric. Sci., 3: 132-137.

10. Mishra, C.N., V. Tiwari, Satish-Kumar, V. Gupta, A. Kumar and I. Sharma, 2015. Genetic diversity and genotype by trait analysis for agro-morphological and physiological traits of wheat (Triticum aestivum L.). SABRAO J. Breed. Genet., 47: 40-48.

11. Mohammadi, R. and A. Amri, 2011. Graphic analysis of trait relations and genotype evaluation in durum wheat. J. Crop Improv., 25: 680-696.

12. Yan, W. and D.H. Wallace, 1995. Breeding for negatively associated traits. Plant Breed. Rev., 13: 141-177.

13. Lewis, R.S., 2006. Identification of germplasm of possible value for confronting an unfavorable inverse genetic correlation in tobacco. Crop Sci., 46: 1764-1771.

14. Yan, W. and I. Rajcan, 2002. Biplot analysis of test sites and trait relations of soybean in Ontario. Crop Sci., 42: 11-20.

15. Ma, B.L., W. Yan, L.M. Dwyer, J. Fregeau-Reid, H.D. Voldeng, Y. Dion and H. Nass, 2004. Graphic analysis of genotype, environment, nitrogen fertilizer and their interactions on spring wheat yield. Agron. J., 96: 169-180.

16. Yan, W. and J. Fregeau-Reid, 2008. Breeding line selection based on multiple traits. Crop Sci., 48: 417-423.

17. AOAC., 2003. Official Methods of Analysis. Association of Official Analytical Chemists. Washington. AOAC, 2003. "Official Methods of Analysis" 13th Edn., Association of Official Analytical Chemists, Washington.

18. Vunchi, M.A., A.N. Umar, M.A. King, A.A. Liman, G. Jeremiah and C.O. Aigbe, 2011. Proximate, vitamins and mineral composition of Vitex doniana (black plum) fruit pulp. Nigerian J. Basic Appl. Sci., 19: 97-101.
19. Odewale, J., A. Collins, C.D. Ataga, E.C. Okolo and C.E. Ikuenobe et al., 2014. Genotype by trait relations between yield and some morphological traits of coconut (Cocos nucifera L.) hybrid varieties based on GT biplot. Int. J. Plant Soil Sci., 3: 270-280.

20. Oyeleke, G.O., A.D. Isola, M.A. Salam and F.D. Ajao, 2013. Evaluation of some chemical composition of pawpaw (Carica papaya) seeds under normal storage ripening. J. Env. Sci., Toxic. and Food Tech., 4: 18-21.

Yan, W., 2001.GGEbiplot-A windows application for graphical analysis of multi environment trial data and other types of two-way data. Agron. J., 93: 1111-1118.

21. Kroonenberg, P. M., 1995. Introduction to biplots for $\mathrm{G} \times \mathrm{E}$ tables. Dept. of Mathematics Res. Rep., 51. Univ. of Queensland, Australia.

22. Rubio, J., J.I. Cubero, L.M. Martin, M.J. Suso and F. Flores, 2004. Biplot analysis of trait relations of white lupin in Spain. Euphytica, 135: 217-224.

23. Sabaghnia, N. and M. Janmohammadi, 2020. Graphic analysis of nano-silicon by salinity stress interaction on germination properties of lentil using the biplot method. Agric. For., 60: 29-40.

24. Badu-Apraku, B., Lum A. Fontem, R.O. Akinwale and M. Oyekunle, 2011. Biplot analysis of diallel crosses of early maturing tropical yellow maize inbreds in stress and nonstress environments. Crop Sci., 51: 173-188.

25. Badu-Apraku B., M. Oyekunle, R.O. Akinwale and A.F. Lum, 2011. Combining ability and heterotic groups of early maturing tropical white maize inbred lines under stress and nonstress environments. Agron. J., 103: 544-557.

26. Oladejo, A.S., R.O. Akinwale and I.O. Obisesan, 2011. Interrelationships between grain yield and other physiological traits of cowpea cultivars. Afr. Crop Sci. J., 19: 189-200.

27. Badu-Apraku, B. and R.O. Akinwale, 2011. Cultivar evaluation and trait analysis of tropical early maturing maize under Striga-infested and Striga-free environments. Field Crops Res., 121: 186-194.

28. Yan, W. and M.S. Kang, 2003. GGE Biplot Analysis: A Graphical Tool for Breeders, Geneticists and Agronomists. 1st Edn., CRC Press, Boca Raton, FL., USA., ISBN-13: 9781420040371, Pages: 288.

29. Akinwale, R.O., M.A.B. Fakorede, B. Badu-Apraku and A. Oluwaranti, 2014. Assessing the usefulness of GGE biplot as a statistical tool for plant breeders and agronomists. Cereal Res. Commun., 42: 534-546.

30. Ding, M. and B. Tier, 2008. Application of GGE biplot analysis to evaluate Genotype (G), Environment (E), and GXE interaction on Pinus radiata: a case study. New Zealand J. For. Sci., 38: 132-142. 